\title{
Whole-cell protein electrophoretic analysis of viridans streptococci : evidence for heterogeneity among Streptococcus mitis biovars
}

\author{
P. Vandamme, ${ }^{1,2}$ U. Torck, ${ }^{1}$ E. Falsen, ${ }^{3}$ B. Pot,${ }^{4} \mathrm{H}$. Goossens ${ }^{2}$ \\ and K. Kersters ${ }^{1}$
}

Author for correspondence: P. Vandamme. Tel: +32926451 13. Fax: +3292645092.

e-mail: Peter.Vandamme@rug.ac.be

\footnotetext{
1,4 Laboratory of

Microbiology 1 , and

BCCM $^{\text {TM/LMG }}$ Culture

Collection ${ }^{4}$,

Ledeganckstraat 35 ,

University of Ghent B-9000 Ghent, Belgium

2 Laboratory of Medical Microbiology, University Hospital Antwerp UIA, Antwerp, Belgium

3 CCUG Culture Collection, Department of Clinical Bacteriology, University of Göteborg, S-413 46 Goteborg, Sweden
}

\begin{abstract}
One hundred reference strains representing all species belonging to the different phylogenetic lineages of the viridans streptococci were examined by means of one-dimensional whole-organism protein electrophoresis. For most of the species examined, multiple strains characterized by DNA-DNA hybridization were included and, wherever described, representatives of different biochemical variants were analysed. Most species were clearly differentiated. The data support the viewpoint that members of the Streptococcus anginosus group constitute a single species and indicate that Streptococcus mitis biovar 2 is a heterogeneous taxon comprising strains from several streptococcal species.
\end{abstract}

Keywords: viridans streptococci, Streptococcus mitis, whole-cell protein analysis

\section{INTRODUCTION}

The differentiation of species belonging to the viridans streptococci has always been tedious, and species-level identification of all of these species is beyond the reach of many laboratories. Amongst the streptococci, several major phylogenetic lineages can be discriminated, four of which comprise viridans species: the Streptococcus anginosus rRNA homology group with the species S. anginosus, Streptococcus intermedius and Streptococcus constellatus; the Streptococcus mitis rRNA homology group with $S$. mitis, Streptococcus oralis, Streptococcus gordonii, Streptococcus sanguis and Streptococcus parasanguis; the Streptococcus mutans rRNA homology group with $S$. mutans, Streptococcus cricetus, Streptococcus downei, Streptococcus ferus, Streptococcus macacae, Streptococcus rattus and Streptococcus sobrinus; and finally, the Streptococcus thermophilus rRNA homology group with $S$. thermophilus, Streptococcus salivarius and Streptococcus vestibularis $(2,9)$. The phylogenetic position of Streptococcus crista is yet to be determined, but this species shares rather high DNA-DNA hybridization values with $S$. sanguis and $S$. gordonii strains, indicating that it belongs to the $S$. mitis rRNA homology group as well (7). In addition, it has been demonstrated that Streptococcus pneumoniae also belongs to the $S$. mitis
rRNA homology group (2). Most pneumococci are however easily identified, have a different pathology and are often not included in comparative studies of viridans streptococci. Pneumococcal reference strains were examined but they did not grow under the conditions used in the present study. The remaining major streptococcal phylogenetic lineages comprise the pyogenic streptococci and the species belonging to the Streptococcus bovis group $(2,9)$.

In previous studies, we demonstrated the ability of comparative whole-organism protein electrophoresis for the differentiation of pyogenic streptococci $(15$, 16). As in many other Gram-positive and Gramnegative bacteria, streptococcal strains with very similar whole-cell protein patterns shared high DNADNA hybridization values as was deduced from the inclusion of strains for which DNA-DNA hybridization data were available. In the present study, we evaluate the suitability of whole-cell protein electrophoresis for the differentiation of viridans streptococci by examining a collection of well-characterized reference strains, including a considerable number of strains for which DNA-DNA hybridization data are available.

Recently, the specific epithets of several streptococcal species were corrected to conform to Rule $12 \mathrm{c}$ of the 
Table 1. Strains examined

\begin{tabular}{|c|c|c|c|}
\hline Strain & Other strain no.* & Reference & Strain information \\
\hline \multicolumn{4}{|l|}{ Streptococcus anginosus group } \\
\hline Streptococcus anginosus LMG $14502^{\mathrm{T}}$ & CCUG 27298, NCTC 10713 & Whiley \& Beighton (20) & Throat \\
\hline Streptococcus anginosus LMG 14696 & CCUG 223, NCTC 8037 & Whiley \& Beighton (20) & Respiratory tract \\
\hline Streptococcus anginosus LMG 17666 & CCUG 28191, LHMC PC4890 & Whiley \& Beighton (20) & Dental plaque \\
\hline Streptococcus anginosus LMG 17832 & CCUG 28192, LHMC NMH 10 & Whiley \& Beighton (20) & Perforated ulcer \\
\hline Streptococcus anginosus LMG 17833 & CCUG 28195, CDC 2236-81 & Whiley \& Beighton (20) & Blood \\
\hline Streptococcus constellatus LMG 14503 & CCUG 4215, NCTC 5389 & Whiley \& Beighton (20) & Unknown \\
\hline Streptococcus constellatus LMG 14504 & CCUG 9569, NCTC 10708 & Whiley \& Beighton (20) & Dental abscess \\
\hline Streptococcus constellatus LMG $14507^{\mathrm{T}}$ & CCUG 24889, NCFB 2226 & Whiley \& Beighton (20) & Purulent pleurisy \\
\hline Streptococcus constellatus LMG 17665 & CCUG 28196, LHMC AM 699 & Whiley \& Beighton (20) & Dental plaque \\
\hline Streptococcus constellatus LMG 17835 & CCUG 28197, LHMC NMH 1 & Whiley \& Beighton (20) & Brain abscess \\
\hline Streptococcus constellatus LMG 17836 & CCUG 28198, LHMC UNS 55 & Whiley \& Beighton (20) & Appendix \\
\hline Streptococcus constellatus LMG 17837 & CCUG 28199, LHMC EF 52 & Whiley \& Beighton (20) & Dental plaque \\
\hline Streptococcus constellatus LMG 17838 & CCUG 28200, LHMC PC 67 & Whiley \& Beighton (20) & Dental plaque \\
\hline Streptococcus constellatus LMG 17839 & CCUG 28201, LHMC NMH 12 & Whiley \& Beighton (20) & Submandibular abscess \\
\hline Streptococcus intermedius $\mathrm{LMG} 17840^{\mathrm{T}}$ & CCUG 17827, NCFB 2227 & Whiley \& Beighton (20) & Unknown \\
\hline Streptococcus intermedius LMG 14548 & CCUG 28203, LHMC NHM 2 & Whiley \& Beighton (20) & Brain abscess \\
\hline Streptococcus intermedius LMG 17841 & CCUG 28204, LHMC GN72 & Whiley \& Beighton (20) & Dental plaque \\
\hline Streptococcus intermedius LMG 14550 & CCUG 28205, LHMC AC4817 & Whiley \& Beighton (20) & Dental plaque \\
\hline \multicolumn{4}{|l|}{ Streptococcus mitis group } \\
\hline Streptococcus cristatus LMG 14512 & LMG 17205, CCUG 30424, LHMC AK1 & Handley et al. (7) & Throat swab \\
\hline Streptococcus cristatus LMG $16320^{\mathrm{T}}$ & CCUG 33481, CR311 & Handley et al. (7) & Periodontal abscess \\
\hline Streptococcus cristatus LMG 17206 & LHMC CCSA & Handley et al. (7) & Dental plaque \\
\hline Streptococcus cristatus LMG 17207 & LHMC CR3 & Handley et al. (7) & Dental plaque \\
\hline Streptococcus cristatus LMG 17842 & & & Human blood \\
\hline Streptococcus gordonii LMG 14515 & CCUG 4216, NCTC 10231, SK 5 & Kilian et al. (10) & (Biovar 2) \\
\hline Streptococcus gordonii LMG 14516 & LMG 14648, CCUG 18374, NCTC 3165, SK 51 & Kilian et al. (10) & (Biovar 3) \\
\hline Streptococcus gordonii LMG 14517 & CCUG 25607, SK 6 & Kilian et al. (10) & (Biovar 1) \\
\hline Streptococcus gordonii LMG $14518^{\mathrm{T}}$ & CCUG 25608, SK 3 & Kilian et al. (10) & Endocarditis (biovar 2) \\
\hline Streptococcus gordonii LMG 14519 & CCUG 27309, SK 86 & Kilian et al. (10) & Dental plaque (biovar 2) \\
\hline Streptococcus gordonii LMG 17843 & CCUG 27509, Carlsson 30 & Carlsson (3) & Human oral cavity \\
\hline Streptococcus gordonii LMG 17844 & CCUG 27510, Carlsson 31 & Carlsson (3) & Human oral cavity \\
\hline Streptococcus gordonii LMG 17845 & CCUG 27511, Carlsson 32 & Carlsson (3) & Human oral cavity \\
\hline Streptococcus gordonii LMG 17846 & CCUG 27515, Carlsson 36 & Carlsson (3) & Human oral cavity \\
\hline Streptococcus mitis LMG 14552 & R-107, $\dagger$ CCUG 4212, NCTC 10712, SK 113 & Kilian et al. (10) & Human sputum (biovar 1 ) \\
\hline Streptococcus mitis LMG 14554 & CCUG 27740, SK 135 & Kilian et al. (10) & Human oral cavity (biovar 1 ) \\
\hline Streptococcus mitis LMG 14555 & CCUG 27741, SK 138 & Kilian et al (10) & Human dental plaque (biovar 1) \\
\hline Streptococcus mitis LMG $14557^{\mathrm{T}}$ & CCUG 31611 , NCTC 12261, SK 142 & Kilian et al. (10) & Human oral cavity (biovar 1) \\
\hline Streptococcus mitis LMG 14553 & CCUG 25611, SK 34 & Kilian et al. (10) & Human oral cavity (biovar 2 ) \\
\hline Streptococcus mitis LMG 14556 & CCUG 27743, SK 79 & Kilian et al. (10) & Human oral cavity (biovar 2) \\
\hline Streptococcus mitis LMG 17594 & CCUG 27742, SK 71 & Kilian et al. (10) & Human oral cavity (biovar 2 ) \\
\hline Streptococcus mitis LMG 17595 & CCUG 21026, SK 132 & Kilian et al. (10) & Ulcerated sore throat (biovar 2) \\
\hline Streptococcus mitis LMG 17596 & CCUG 35789, SK 96 & Kilian et al. (10) & Human oral cavity (biovar 2) \\
\hline Streptococcus mitis LMG 17597 & CCUG 35792, SK 148 & Kilian et al. (10) & Human dental plaque (biovar 2) \\
\hline Streptococcus oralis LMG $14532^{\mathrm{T}}$ & CCUG 24891, SK 23 & Kilian et al. (10) & Human oral cavity \\
\hline Streptococcus oralis LMG 14533 & LMG 14649, CCUG 24892, SK 2, ATCC 10557 & Kilian et al. (10) & Endocarditis \\
\hline Streptococcus oralis LMG 14534 & CCUG 27680, Carlsson 50 & Carlsson (3) & Human oral cavity \\
\hline Streptococcus oralis LMG 14535 & CCUG 27681, Carlsson 51 & Carlsson (3) & Human oral cavity \\
\hline Streptococcus oralis LMG 14536 & CCUG 27682, Carlsson 39 & Carlsson (3) & Human oral cavity \\
\hline Streptococcus oralis LMG 17851 & CCUG 27679, Carlsson 49 & Carlsson (3) & Human oral cavity \\
\hline Streptococcus parasanguinis LMG $14537^{\mathrm{T}}$ & CCUG 30417, LHMC SS898 & Whiley et al. (21) & Throat \\
\hline Streptococcus parasanguinis LMG 14538 & R-112,† CCUG 30418, LHMC SS897 & Whiley et al. (21) & Throat \\
\hline Streptococcus parasanguinis LMG 14539 & CCUG 30419, LHMC 2059-87 & Whiley et al. (21) & Blood \\
\hline Streptococcus parasanguinis LMG 14540 & CCUG 30420, LHMC 2156-81 & Whiley et al. (21) & Blood \\
\hline Streptococcus parasanguinis LMG 17852 & CCUG 30423, LHMC MGH 413 & Whiley et al. (21) & Urine \\
\hline Streptococcus parasanguinis LMG 17853 & CCUG 30422, LHMC MGH 143 & Whiley et al. (21) & Urine \\
\hline Streptococcus sanguinis LMG 14637 & $\mathrm{R}-105, \dagger$ CCUG 25606, SK 45 & Kilian et al. (10) & Human dental plaque (biovar 4) \\
\hline Streptococcus sanguinis LMG 14638 & R-115,† CCUG 27744, SK 72 & Kilian et al. (10) & Human dental plaque (biovar 1) \\
\hline Streptococcus sanguinis LMG 14639 & R-116,† CCUG 27745, SK 77 & Kilian et al. (10) & Human dental plaque (biovar 1) \\
\hline Streptococcus sanguinis LMG 14656 & CCUG 25604, SK 164 & Kilian et al. (10) & Human dental plaque (biovar 2) \\
\hline Streptococcus sanguinis LMG 14657 & CCUG 25605, SK 150 & Kilian et al. (10) & Human dental plaque (biovar 3 ) \\
\hline Streptococcus sanguinis LMG $14702^{\top}$ & R-104, †CUG 17826, ATCC 10556, SK1 & Kilian et al. (10) & Endocarditis (biovar 1) \\
\hline \multicolumn{4}{|l|}{ Streptococcus mutans group } \\
\hline Streptococcus cricetus LMG $14508^{\mathrm{T}}$ & CCUG 27300 , NCFB 2720 , strain HS6 & Coykendali (4) & Hamster caries lesion \\
\hline Streptococcus cricetus LMG 14511 & CCUG 28071, strain AHT & Coykendall (4) & Human caries lesion \\
\hline Streptococcus downei LMG $14514^{\mathrm{T}}$ & CCUG 24890, NCTC 11391 & Whiley et al. (19) & Dental plaque, monkey \\
\hline Streptococcus ferus LMG $16520^{\mathrm{T}}$ & CCUG 34784, DSM 20646 & Coykendall (5) & Oral cavity, rat \\
\hline Streptococcus macacae LMG $15097^{\mathrm{T}}$ & NCTC 11558, strain $25-1$ & Beighton et al. (1) & Dental plaque, monkey \\
\hline Streptococcus mutans LMG $14558^{\mathrm{T}}$ & CCUG 11877, NCTC 10449 & Coykendall (4) & Human decayed tooth \\
\hline Streptococcus mutans LMG 14560 & CCUG 32092 & & Human blood, endocarditis \\
\hline Streptococcus ratti LMG $14650^{\mathrm{T}}$ & CCUG 27502, ATCC 19645 & Coykendall (4) & Laboratory rat \\
\hline Streptococcus ratti LMG 14651 & CCUG 27641, strain BHT & Coykendall (4) & Human \\
\hline Streptococcus sobrinus LMG $14641^{\mathrm{r}}$ & CCUG 24717, DSM 20742 & Coykendall (5) & Human dental plaque \\
\hline Streptococcus sobrinus LMG 14640 & CCUG 21019, NCTC 10921 & Coykendall (5) & Human dental plaque \\
\hline
\end{tabular}


Table 1 (cont.)

\begin{tabular}{|c|c|c|c|}
\hline Strain & Other strain no.* & Reference & Strain information \\
\hline \multicolumn{4}{|l|}{ Streptococcus thermophilus group } \\
\hline Streptococcus salivarius LMG $11489^{\mathrm{T}}$ & NCFB 1779 , CCUG 17825 & Whiley \& Hardie (22) & Human blood \\
\hline Streptococcus salivarius LMG 13103 & NCFB 1777 & & Unknown \\
\hline Streptococcus salivarius LMG 14652 & CCUG 32152 & & Human blood \\
\hline Streptococcus salivarius LMG 14653 & CCUG 32452 & & Human blood \\
\hline Streptococcus salivarius LMG 13108 & NCFB 2701, strain A 385 & & Unknown \\
\hline Streptococcus salivarius LMG 13107 & NCFB 2700, strain M36 & Whiley \& Hardie (22) & Unknown \\
\hline Streptococcus thermophilus LMG 7952 & NCFB 574 & & Pasteurized milk \\
\hline Streptococcus thermophilus LMG 7953 & NCFB 575 & & Pasteurized milk \\
\hline Streptococcus thermophilus LMG 13100 & NCFB 1242 & & Unknown \\
\hline Streptococcus thermophilus LMG 13101 & NCFB 489 & & Unknown \\
\hline Streptococcus thermophilus LMG $13102^{T}$ & NCFB 573, CCUG 21957 & Schleifer et al. (10) & Pasteurized milk \\
\hline Streptococcus vestibularis LMG $13516^{\mathrm{T}}$ & CCUG 24893, MM1, NCTC 12166 & Whiley \& Hardie (22) & Human vestibular mucosa \\
\hline Streptococcus vestibularis LMG 14645 & CCUG 24684, LV71, Carlsson 85 & Whiley \& Hardie (22) & Human vestibular mucosa \\
\hline Streptococcus vestibularis LMG 14646 & CCUG 24685, PV91, Carlsson 86 & Whiley \& Hardie (22) & Human vestibular mucosa \\
\hline Streptococcus vestibularis LMG 14647 & CCUG 24686, LV81, Carlsson 87 & Whiley \& Hardie (22) & Human vestibular mucosa \\
\hline Streptococcus vestibularis LMG 17854 & R-410, $†$ CCUG 24683, OV71, Carlsson 83 & Whiley \& Hardie (22) & Human vestibular mucosa \\
\hline Streptococcus vestibularis LMG 17855 & CCUG 24687, HV 81, Carlsson 88 & Whiley \& Hardie (22) & Human vestibular mucosa \\
\hline Streptococcus vestibularis LMG 17856 & R-411, † CCUG 24688, OP81, Carlsson 89 & Whiley \& Hardie (22) & Human vestibular mucosa \\
\hline
\end{tabular}

* ATCC, American Type Culture Collection, Rockville, MD, USA; CCUG, Culture Collection University of Göteborg, Department of Clinical Bacteriology, Göteborg, Sweden; CDC, Centers for Disease Control and Prevention, Atlanta, GA, USA; DSM, Deutsche Sammlung von Mikroorganismen und Zellkulturen GmbH, Braunschweig, Germany; LHMC, Department of Oral Microbiology, the Royal London Hospital Medical College, London, UK; LMG, BCCM/LMG Culture Collection, Laboratorium voor Microbiologie Gent, Universiteit Gent, Belgium; NCFB, The National Collection of Food Bacteria, Agricultural and Food Research Council, Institute of Food Research, Reading Laboratory, Reading, UK; NCTC, National Collection of Type Cultures, Central Public Health Laboratory, London, UK; NMH, M. W. D. Wren, North Middlesex Hospital, London, UK; UNS, P. Unsworth, Central Public Health Laboratory, Colindale, London, UK.

† Strains included in a research collection of the Laboratorium voor Microbiologie, Universiteit Gent, Belgium.

International Code of Nomenclature of Bacteria (14). The names Streptococcus cristatus, Streptococcus ratti, Streptococcus sanguinis and Streptococcus parasanguinis were proposed for the former S. crista, S. rattus, $S$. sanguis and $S$. parasanguis, and will be used throughout the present manuscript.

\section{METHODS}

Bacterial strains. All strains examined are listed in Table 1. The majority of the strains examined are type and wellcharacterized reference strains included in various taxonomic studies of viridans streptococci. Appropriate references are listed in Table 1. Bacteriological purity was checked by plating and examining living and Gram-stained cells.

Whole-cell protein analysis. All strains were grown for $24 \mathrm{~h}$ on Brain-Heart Infusion agar (Difco) and incubated at $36-37{ }^{\circ} \mathrm{C}$ in a microaerobic atmosphere containing approximately $5 \% \mathrm{O}_{2}, 10 \% \mathrm{CO}_{2}$ and $85 \% \mathrm{~N}_{2}$. Preparation of cellular protein extracts and PAGE were performed as described previously (12). Briefly, discontinuous gels $(1.5 \mathrm{~mm}$ thick) were run overnight at constant current $(6 \mathrm{~mA}$ per gel) and temperature in a vertical slab apparatus. The separation gel was $12.6 \mathrm{~cm}$ long and contained $12 \%$ total acrylamide [the monomer solution contained $30 \%$ total acrylamide with $2.67 \%$ cross-linking in $0.375 \mathrm{M}$ Tris $/ \mathrm{HCl}$ (pH 8.8 ) and $0.1 \%$ SDS]; the stacking gel was $12 \mathrm{~mm}$ long and contained $5 \%$ total acrylamide [the monomer solution again contained $30 \%$ total acrylamide with $2.67 \%$ crosslinking in $0.125 \mathrm{M}$ Tris $/ \mathrm{HCl}(\mathrm{pH} \mathrm{6.8)}$ and $0.1 \%$ SDS]
Protein bands are stained with Coomassie blue R-250 in $50 \%(\mathrm{v} / \mathrm{v})$ methanol and $10 \%(\mathrm{v} / \mathrm{v})$ acetic acid. These conditions allow separation of proteins and peptides in the molecular mass range of $14-116 \mathrm{kDa}$.

The densitometric analysis, normalization and interpolation of the protein profiles, and numerical analysis were performed using the GelCompar 4.0 software package (Applied Maths, Kortrijk, Belgium).

\section{RESULTS}

\section{Reproducibility}

The reproducibility of the method was verified by running the same extracts on multiple gels and by including duplicate cultures of 11 strains (duplicate cultures are subcultures of the same strain, received on different occasions or from different depositors) (see Table 1). The inter-run reproducibility was at least $94 \%$ (data not shown). Duplicate cultures always belong to the same cluster and group closely together (Fig. 1). The similarity level between these pairs of patterns was always higher than $91 \%$.

\section{Cluster analysis of the protein patterns of the strains examined}

Fig. 1 is a dendrogram obtained after numerical comparison and cluster analysis of the protein patterns of all strains examined. In this analysis, all reference 


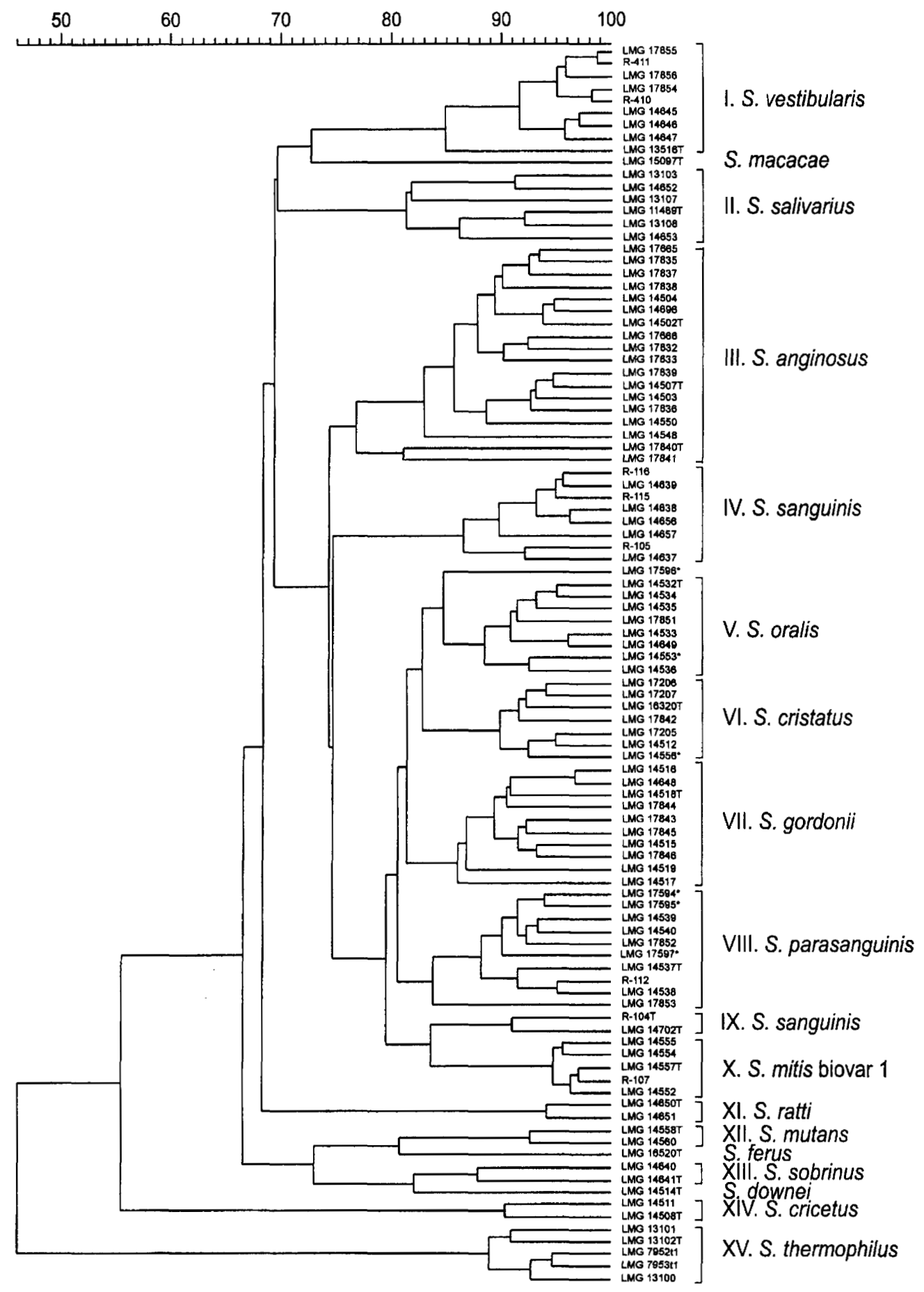

Fig. 1. Dendrogram derived from the unweighted pair group average linkage of correlation coefficients (expressed for convenience as a percentage) between whole-cell protein patterns of all of the strains examined. Strains marked by an asterisk were received as $S$. mitis biovar 2 .

strains of the $S$. anginosus rRNA homology group form a single protein electrophoretic cluster (cluster III). Whole-cell protein patterns of representative strains are shown in Fig. 2.

The three species of the $S$. thermophilus rRNA homology group each constitute a clearly separated protein electrophoretic cluster (cluster I, S. vestibularis; cluster II, S. salivarius; cluster XV, S. thermophilus). Wholecell protein patterns of representative strains are shown in Fig. 3.

Most of the species of the S. mitis rRNA homology group each constitute a distinct protein electrophoretic 

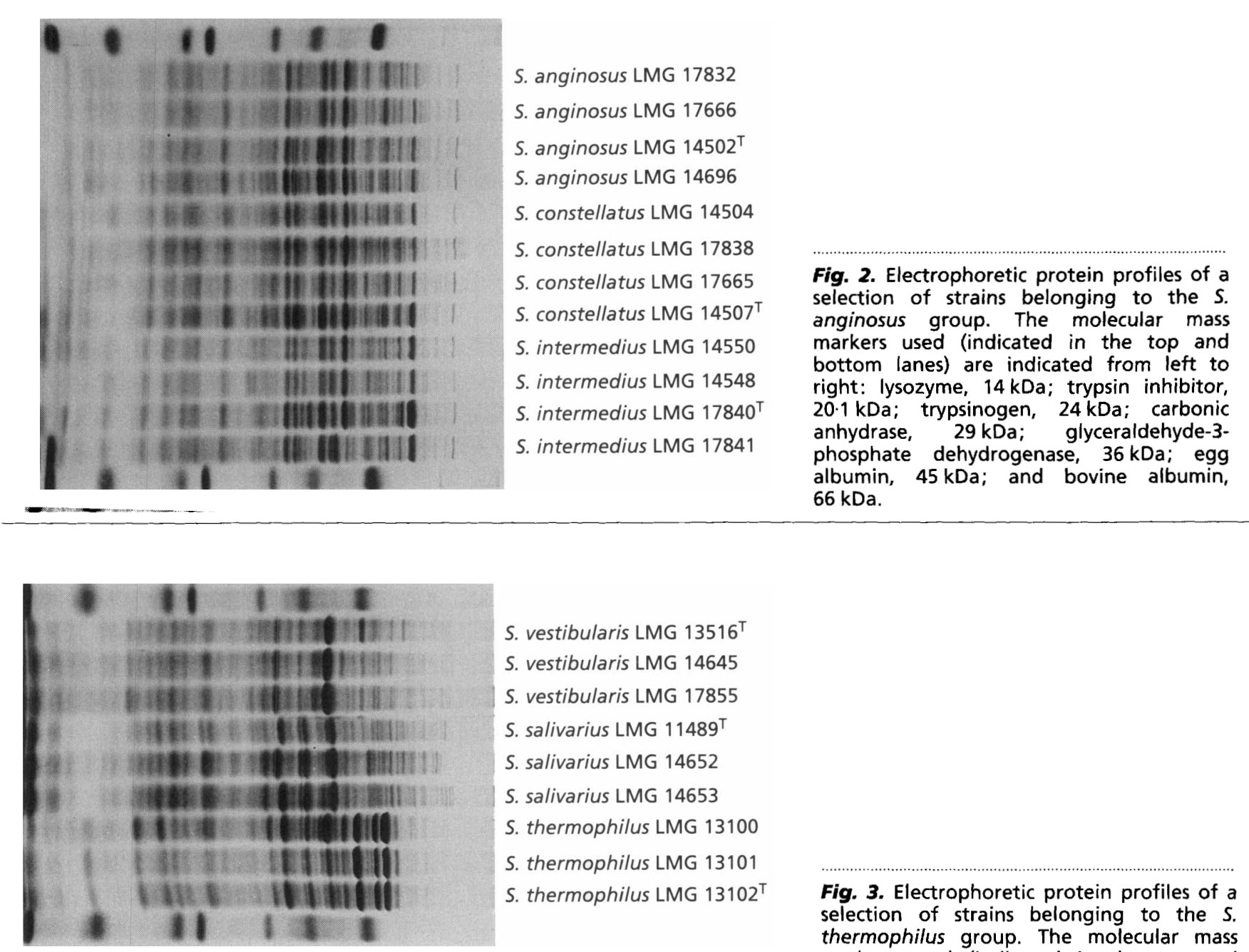

S. vestibularis LMG $13516^{\top}$

S. vestibularis LMG 14645

S. vestibularis $\mathrm{LMG} 17855$

S. salivarius LMG $11489^{\top}$

S. salivarius LMG 14652

S. salivarius LMG 14653

S. thermophilus LMG 13100

S. thermophilus LMG 13101

S. thermophilus LMG $13102^{\top}$
Fig. 3. Electrophoretic protein profiles of a selection of strains belonging to the $S$. thermophilus group. The molecular mass markers used (indicated in the top and bottom lanes) are as in Fig. 2. cluster: S. oralis (cluster V), S. cristatus (cluster VI), $S$. gordonii (cluster VII) and $S$. parasanguinis (cluster VIII). Whole-cell protein patterns of representative strains are shown in Fig. 4. S. sanguinis strains are separated into two distinct clusters: cluster IV contains the majority of strains, whereas cluster IX comprises the two subcultures of the type strain. All S. mitis biovar 1 strains constitute a single protein electrophoretic cluster (cluster X). However, S. mitis biovar 2 strains are distributed over several clusters. One strain (LMG 14553) belongs to the $S$. oralis cluster; a second strain (LMG 17596) groups near the $S$. oralis cluster; one strain (LMG 14556) belongs to the $S$. cristatus cluster; and three strains (LMG 17594, 17595 and 17597 ) belong to the $S$. parasanguinis cluster.

Finally, species of the $S$. mutans rRNA homology group occupy distinct positions in the dendrogram. $S$. mutans, $S$. cricetus, $S$. sobrinus and $S$. ratti strains form separate protein electrophoretic clusters (clusters XII, XIV, XIII and XI, respectively), while the type strains of $S$. macacae, $S$. downei and $S$. ferus occupy distinct positions in the dendrogram (only a single strain of these species was examined). Whole-cell protein patterns of representative strains are shown in Fig. 5.

\section{DISCUSSION}

In previous studies on the relationships of pyogenic streptococci, results of whole-organism protein electrophoresis correlated with those of DNA-DNA hybridization experiments, i.e. strains with very similar whole-cell protein patterns shared high DNA-DNA hybridization values $(15,16)$. The aim of the present study was to evaluate whether whole-cell protein electrophoresis could be used as a method for specieslevel identification for the viridans streptococci. For this purpose, we collected 100 type and well-characterized reference strains of the various species. Most of these strains were included in previous taxonomic studies and, per species, several DNA-DNA hybridization data were available. 


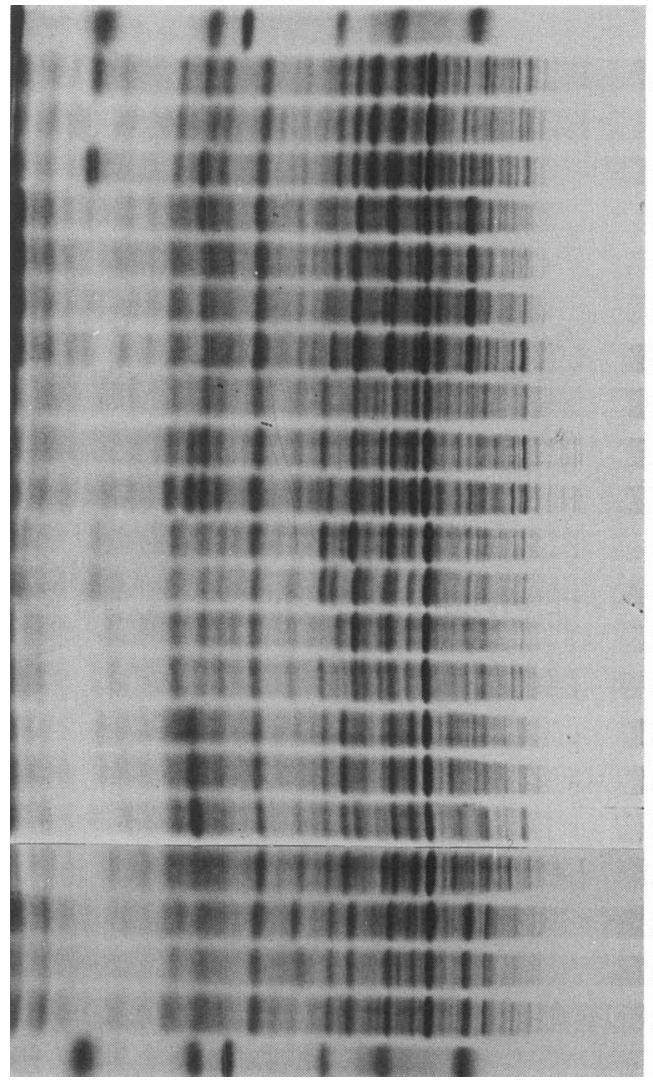

S. cristatus LMG $16320^{\top}$

S. cristatus LMG 17206

S. cristatus LMG 17207

S. oralis LMG $14532^{\top}$

S. oralis LMG 14533

S. oralis LMG 14536

S. mitis biovar 2 LMG 14553

S. gordonii LMG $14518^{\top}$

S. gordonii LMG 17843

S. gordonii LMG 14515

S. parasanguinis LMG $14537^{\top}$

S. parasanguinis LMG 14538

S. parasanguinis LMG 14539

S. mitis biovar 2 LMG 17594

S. sanguinis LMG 14639

S. sanguinis LMG 14638

S. sanguinis LMG 14637

S. sanguinis LMG $14702^{\top}$

S. mitis biovar 1 LMG $14557^{\top}$

S. mitis biovar 1 LMG 14552

S. mitis biovar 1 LMG 14554
Fig. 4. Electrophoretic protein profiles of a selection of strains belonging to the $S$. mitis group. The molecular mass markers used (indicated in the top and bottom lanes) are indicated from left to right: trypsin inhibitor, $20.1 \mathrm{kDa}$; trypsinogen, $24 \mathrm{kDa}$; carbonic anhydrase, $29 \mathrm{kDa}$; glyceraldehyde3-phosphate dehydrogenase, $36 \mathrm{kDa}$; egg albumin, $45 \mathrm{kDa}$; and bovine albumin, $66 \mathrm{kDa}$.

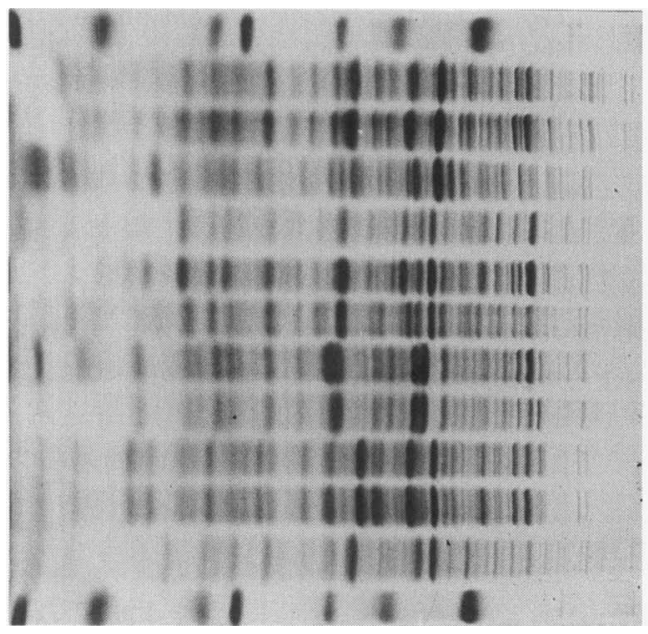

S. mutans LMG $14558^{\top}$

S. mutans LMG 14560

S. ferus LMG $16520^{\top}$

S. sobrinus LMG 14640

S. sobrinus LMG $14641^{\top}$

S. downei LMG $14514^{\top}$

S. cricetus LMG 14511

S. cricetus LMG $14508^{\top}$

S. ratti LMG $14650^{\top}$

S. ratti LMG 14651

S. macacae LMG $15097^{\top}$
Fig. 5. Electrophoretic protein profiles of strains belonging to the 5 . mutans group. The molecular mass markers used (indicated in the top and bottom lanes) are as in Fig. 2.

\section{The S. mitis rRNA homology group (excluding $S$. pneumoniae)}

The taxonomic relationships between some members of the $S$. mitis rRNA homology group were studied in detail by Kilian et al. (10). These authors described or emended the description of $S$. mitis, $S$. oralis, $S$. gordonii and $S$. sanguinis, and delineated multiple biovars in several of these species. Their revised classification was based on an extensive phenotypic analysis and on a compilation of published DNA-
DNA hybridization values amongst well-chosen strains.

S. sanguinis. Four biovars were described within $S$. sanguinis. Strains of two of these (biovars 1 and 2) were proven by DNA-DNA hybridization experiments to constitute a single species, whereas no DNA-DNA hybridization data were available for strains of biovars 3 and 4 . Of all of the $S$. sanguinis strains examined, the type strain (LMG 14702) was the most aberrant (10). In our analysis, six strains studied by Kilian et al. (10) 
representing all four biovars were included. We found that five of these strains (and duplicate cultures of three of them) representing the four biovars formed a single protein electrophoretic cluster (cluster IV, Fig. 1). The type strain, however, differed from the others by the absence of a prominent protein band with an approximate molecular mass of $24 \mathrm{kDa}$ (Fig. 4). As a consequence, both subcultures of the type strain cluster separately in the dendrogram (cluster IX) in the vicinity of $S$. mitis biovar 1 strains (cluster X). These protein electrophoretic data therefore confirm the aberrant nature of the $S$. sanguinis type strain and suggest that strains of biovars 3 and 4 share high DNA-DNA hybridization levels with strains of biovars 1 and 2 .

S. gordonii. Three biovars were described within $S$. gordonii. Strains representing all three biovars were included in DNA-DNA hybridization analyses which demonstrated that they formed a single species.

In our analysis, five strains studied by Kilian et al. (10) representing all three biovars were included. All five strains (and duplicate cultures of one) and the strains LMG 17843 through LMG 17846 formed a single homogeneous cluster VII. The latter four strains were received as $S$. gordonii from J. Carlsson and were included in a numerical taxonomic study of oral streptococci where they were classified as cluster I:B (3). Carlsson's cluster I: B is therefore not synonymous to $S$. sanguinis as discussed by Kilian et al. (10). In our analysis, the former type strain of $S$. mitis (LMG 14516) which was reclassified as $S$. gordonii $(10,18)$, behaved as a typical $S$. gordonii strain, in contrast with some of its other phenotypic characteristics (10).

S. oralis. $S$. oralis does not comprise multiple biovars. We included two representative strains examined by Kilian et al. (10) and four strains from Carlsson's study representing Carlsson's cluster I: A (3). All six strains (and duplicate cultures of one) formed a single homogeneous cluster $\mathrm{V}$ which also comprised strain $S$. mitis LMG 14553 (see below).

S. mitis. Two biovars were delineated within $S$. mitis. Strains representing $S$. mitis biovar 1 were included in DNA-DNA hybridization analyses and proved to constitute a single species (10). Thirteen additional isolates were classified as $S$. mitis biovar $2(10)$. However, DNA-DNA hybridization data confirming that these strains belonged to $S$. mitis were not available and important phenotypic variability was found, suggesting that biovar 2 was heterogeneous (10).

In our analysis, four of the $S$. mitis biovar 1 strains were included. These four strains (and duplicate cultures of one) formed a single homogeneous cluster $X$. However, the six $S$. mitis biovar 2 strains which were examined did not cluster with $S$. mitis biovar 1 strains, nor did they constitute a single phenon. Three of these strains belonged to the $S$. parasanguinis cluster and one belonged to the $S$. cristatus cluster (Figs 1 and
4). Neither species had been described when Kilian's study was published $(7,21)$. Finally, one of the strains (LMG 14553) belonged to the $S$. oralis cluster (Figs 1 and 4), while another strain (LMG 17849) occupied a distinct position in the dendrogram with $S$. oralis as its closest neighbour. Obviously, S. mitis biovar 2 is a heterogeneous taxon and our results suggest that strains classified as such may belong to various other streptococcal species.

S. parasanguinis. $S$. parasanguinis was described by Whiley et al. (21) for ten strains tentatively classified in the $S$. anginosus species group (23). All strains shared high DNA-DNA binding values with $S$. sanguinis as closest relative. In the present analysis, we included six of these strains (and duplicate cultures of one) which all formed a single homogeneous cluster (cluster VIII).

S. cristatus. Similarly, S. cristatus was described by Handley et al. (7) for four strains superficially resembling $S$. sanguinis and previously referred to as 'the CR group' or the 'tufted fibril group'. Three of these strains were examined by DNA-DNA hybridization and showed high hybridization values. All four strains (including duplicate cultures of one) and a recent human blood isolate also formed a single homogeneous protein electrophoretic cluster (cluster VI).

\section{The S. anginosus rRNA homology group}

The taxonomic status of strains classified as $S$. anginosus, $S$. constellatus and $S$. intermedius has been the subject of much debate [reviewed by Whiley \& Beighton (20)]. One view is that these three taxa are phenotypically virtually indistinguishable and that, in spite of some genotypic heterogeneity, they constitute a single species, $S$. anginosus (6). The other view is that there are sufficient differential phenotypic characteristics between these three taxa and that the DNADNA hybridization levels between the three groups are sufficiently low to warrant their classification as three distinct species (20). The reported DNA-DNA hybridization levels between the three named species are often near the borderline of species delimitation, while the phenotypic differentiation between at least two groups is not straightforward $[S$. intermedius is readily differentiated from the others using the scheme of Whiley \& Beighton (20)]. Group-specific polypeptide patterns (peptides in the molecular mass range of $25.5-34 \mathrm{kDa}$, i.e. the low-molecular-mass region) as revealed by SDS-PAGE (23), 16S rRNA probe hybridization results (8) and Py-MS (11) support the distribution of these isolates in three, four or five subgroups, respectively.

In our protein electrophoretic analysis, we included five strains classified by Whiley \& Beighton (20) as $S$. anginosus, nine as $S$. constellatus and four as $S$. intermedius. Whereas numerical analysis of whole-cell protein patterns enabled clear differentiation between all other streptococcal species, these 18 isolates formed a single, though heterogeneous, cluster (cluster III) (Fig. 1). Fig. 4 illustrates the whole-cell protein 
patterns of four reference strains of each of these taxa. The $S$. intermedius strains were clearly the most aberrant ones (the differences between $S$. intermedius strains and strains from the other two species are mainly situated in the region between the $20 \cdot 1$ and $24 \mathrm{kDa}$ marker proteins) but there was no clear subdivison in three taxa, not even when the analysis was restricted to the low-molecular-mass region of the protein patterns (23) (data not shown). It is wellknown that culture conditions and electrophoretic conditions may influence the protein patterns as revealed by SDS-PAGE. The discrepancy between the results from our study and the one of Whiley and Hardie (23) may be due to different conditions used. However, as discussed above, the conditions used in our laboratory generate protein patterns which correlate with DNA-DNA hybridization results as demonstrated for a wide variety of both Gram-negative and Gram-positive species (17), including the majority of streptococcal species $(15,16$, this study). It is therefore not unlikely that the differences between polypeptide patterns as revealed in the study by Whiley \& Beighton (20) correspond to infraspecific subdivisions of a single species.

We conclude that our analysis of whole-cell protein patterns supports the viewpoint that these three taxa constitute a single species which should be referred to as $S$. anginosus (6).

\section{The S. thermophilus rRNA homology group}

The $S$. thermophilus, $S$. salivarius and $S$. vestibularis reference strains constitute distinct protein electrophoretic clusters each (Figs 1 and 3), confirming that also within the $S$. thermophilus rRNA homology group, whole-cell protein electrophoresis allows a clear-cut species differentiation.

\section{The S. mutans rRNA homology group}

Few reference strains of species belonging to the $S$. mutans rRNA homology group were included. Wholecell protein analysis was used by Beighton et al. (1) for the differentiation of mutans streptococci and was found appropriate. In our analysis we found considerable similarities between $S$. downei $\mathrm{LMG} 14514^{\mathrm{T}}$ and $S$. sobrinus strains (Figs 1 and 5), while all other species were clearly identifiable.

\section{Conclusion}

In previous studies we demonstrated that members of the pyogenic species group (Streptococcus agalactiae, Streptococcus canis, Streptococcus dysgalactiae, Streptococcus equi, Streptococcus iniae, Streptococcus parauberis, Streptococcus phocae, Streptococcus porcinus, Streptococcus pyogenes and Streptococcus uberis) could all be differentiated by means of whole-cell protein electrophoresis $(15,16)$. In the present study, we included 100 strains representing all 19 species belonging to the different phylogenetic lineages of the so-called viridans or oral streptococci. For most of the species examined, multiple strains characterized by DNA-DNA hybridization were available and, wherever described, representatives of different biochemical variants were included. The differentiation of most of these species by means of SDS-PAGE of cellular proteins was straightforward. Problems were only encountered in the $S$. anginosus rRNA homology group and in $S$. mitis, and our data confirmed the aberrant nature of the $S$. sanguinis type strain. Our data support the viewpoint that members of the $S$. anginosus group constitute a single species and indicate that $S$. mitis biovar 2 is a heterogeneous taxon comprising strains from several streptococcal species.

\section{ACKNOWLEDGEMENTS}

P.V. and K.K. are indebted to the Fund for Scientific Research - Flanders (Belgium) for a position as a postdoctoral fellow, and research and personnel grants, respectively. Our research was also supported by the Prime Minister's Services - Federal Office for Scientific, Technical and Cultural Affairs, Belgium. We are grateful to all depositors of strains examined.

\section{REFERENCES}

1. Beighton, D., Hayday, H., Russell, R. R. B. \& Whiley, R. A. (1984). Streptococcus macacae sp. nov., from dental plaque of monkeys (Macacae fascicularis). Int J Syst Bacteriol 34, 332-335.

2. Bentley, R. W., Leigh, J. A. \& Collins, M. D. (1991). Intrageneric structure of Streptococcus based on comparative analysis of small-subunit rRNA sequences. Int $J$ Syst Bacteriol 41, 487-494.

3. Carlsson, J. (1968). A numerical taxonomic study of human oral streptococci. Odontol Revy 19, 137-160.

4. Coykendall, A. (1977). Proposal to elevate the subspecies of Streptococcus mutans to species status, based on their molecular composition. Int J Syst Bacteriol 27, 26-30.

5. Coykendall, A. (1983). Streptococcus sobrinus nom. rev. and Streptococcus ferus nom. rev.: habitat of these and other mutans streptococci. Int $J$ Syst Bacteriol 33, 883-885.

6. Coykendall, A. L., Wesbecher, P. M. \& Gustafson, K. B. (1987). 'Streptococcus milleri', Streptococcus constellatus, and Streptococcus intermedius are later synonyms of Streptococcus anginosus. Int J Syst Bacteriol 37, 222-228.

7. Handley, P., Coykendall, A., Beighton, D., Hardie, J. M. \& Whiley, R. A. (1991). Streptococcus crista sp. nov., a viridans streptococcus with tufted fibrils, isolated from the human oral cavity and throat. Int $J$ Syst Bacteriol 41, 543-547.

8. Jacobs, J. A., Schot, C. S., Bunschoten, A. E. \& Schouls, L. M. (1996). Rapid species identification of 'Streptococcus milleri' strains by line blot hybridization: identification of a distinct 16S rRNA population closely related to Streptococcus constellatus. J Clin Microbiol 34, 1717-1721.

9. Kawamura, Y., Hou, X.-G., Sultana, F., Miura, H. \& Ezaki, T. (1995). Determination of 16S rRNA sequences of Streptococcus mitis and Streptococcus gordonii and phylogenetic relationships among members of the genus Streptococcus. Int J Syst Bacteriol 45, 406-408. 
10. Kilian, M., Mikkelsen, L. \& Henrichsen, J. (1989). Taxonomic study of viridans streptococci : description of Streptococcus gordonii sp. nov. and emended descriptions of Streptococcus sanguis (White and Niven 1946), Streptococcus oralis (Bridge and Sneath 1982), and Streptococcus mitis (Andrewes and Horder 1906). Int J Syst Bacteriol 39, $471-484$

11. Magee, J. T., Hindmarch, J. M. \& Douglas, C. W. I. (1997). A numerical taxonomic study of Streptococcus sanguis, Streptococcus mitis, and similar organisms using conventional tests and pyrolysis mass spectrometry. Zentrabl Bakteriol 285, 195-203.

12. Pot, B., Vandamme, P. \& Kersters, K. (1994). Analysis of electrophoretic whole-organism protein fingerprints. In Modern Microbial Methods: Chemical Methods in Prokaryotic Systematics, pp. 493-521. Edited by M. Goodfellow \& A. G. O'Donnell. Wiley: Chichester.

13. Schleifer, K.-H., Ehrmann, M., Krusch, U. \& Neve, H. (1991). Revival of the species Streptococcus thermophilus (ex OrlaJensen, 1919) nom. rev. Syst Appl Microbiol 14, 386-388.

14. Trüper, H. G. \& De'Clari, L. (1997). Taxonomic note: necessary correction of specific epithets formed as substantives (nouns) 'in apposition'. Int J Syst Bacteriol 47, 908-909.

15. Vandamme, P., Devriese, L. A., Pot, B., Kersters, K. \& Melin, P. (1997). Streptococcus difficile is a nonhemolytic group B, type Ib streptococcus. Int J Syst Bacteriol 47, 81-85.

16. Vandamme, P., Pot, B., Falsen, E., Kersters, K. \& Devriese, L. A. (1996). Taxonomic study of Lancefield streptococcal groups C, G, and L (Streptococcus dysgalactiae) and proposal of $S$. dysgalactiae subsp. equisimilis subsp. nov. Int $J$ Syst Bacteriol 46, 774-781.

17. Vandamme, P., Pot, B., Gillis, M., De Vos, P., Kersters, K. \& Swings, J. (1996). Polyphasic taxonomy, a consensus approach to bacterial classification. Microbiol Rev 60, 407438.

18. Wayne, L. G. (1994). Actions of the Judicial Commission of the International Committee on Systematic Bacteriology on requests for opinions published between January 1985 and July 1993. Int $J$ Syst Bacteriol 44, 177-178.

19. Whiley, R. A., Russell, R. R. B., Hardie, J. M. \& Beighton, D. (1988). Streptococcus downei sp. nov. for strains previously described as Streptococcus mutans serotype h. Int J Syst Bacteriol 38, 25-29.

20. Whiley, R. A. \& Beighton, D. (1991). Emended descriptions and recognition of Streptococcus constellatus, Streptococcus intermedius, and Streptococcus anginosus as distinct species. Int $J$ Syst Bacteriol 41, 1-5.

21. Whiley, R. A., Fraser, H. Y., Douglas, C. W. I., Hardie, J. M., Williams, A. M. \& Collins, M. D. (1990). Streptococcus parasanguis sp. nov., an atypical viridans Streptococcus from human clinical specimens. FEMS Microbiol Lett 68, 115122.

22. Whiley, R. A. \& Hardie, J. M. (1988). Streptococcus vestibularis sp. nov. from the human oral cavity. Int $J$ Syst Bacteriol 38, 335-339.

23. Whiley, R. A. \& Hardie, J. M. (1989). DNA-DNA hybridization studies and phenotypic characteristics of strains within the 'Streptococcus milleri' group. J Gen Microbiol 135, 2623-2633. 